\section{Collaborate to innovate}

How the InSPIRE Center at UCLan Cyprus brings together academics and industry

The Center of Interdisciplinary Science Promotion \& Innovation Research Exploration (InSPRRE) at UCLan Cyprus aims to enhance scientific research Explor projects, educational activities and community engagement. InSPIRE's founder, Dr Panayiotis Andreou, believes it is essential that the two sides work together if they want to stay at the cutting-edge of research, and that all parties benefit from such relationships.

\section{r Panayiotis Andreou had how a collaborative approach by academics and industry leaders} could be better applied to result in the mutual benefit of both parties. Any industry organisation could benefit from graduates who had genuine and valuable work experience, as well as an understanding of how commercia research works. And academics could benefit from industry partnerships that would better help them understand the poal societal impact of their research, or valuable lines of inquiry.

But how could he bring the two together? In 2015 he co-founded the Promotion \& Innovation Research Exploration (InSPIRE) to do just that. an interview with Dr Andreou, Research Outreach found out more.

What are the main goals and strategies of the Center of Interdisciplinary Science Promotion \& Innovation The InSPIRE Center was founded in 2015 by academics and industry associates with the mission to support of scientif rent and development a culture of esnovative establshing a culure of innovative partnerships to enable the utilisation of state-of-theresponsible research and innovative activities, with an emphasis on the areas of Science, Technology, Engineering and Mathematics (STEM). To achieve the Center's vision, its resident members work closely with internationally respected and distinguished researchers, academics, industry professionals and policy makers to fos knowledge transfer, enrich studen envionments, and cullivate clizens

To this end, the Center focuses on activities related to high impact research activities related to high impact

enhancement of students' knowledge development of collaborative res and industry projects, promotion of STEM education, awareness on the mpact of STEM research and teaching and the organisation of research seminars, workshops and professional training for the community. InSPIRE members are internationally recognised for research and innovation and they externally funded projects, including EU H2020, Erasmust and Cyprus funded projects. In the past, they have learning experiences and academic and practical skills, through the are currently participating in different Research Promotion Foundation (RPF)

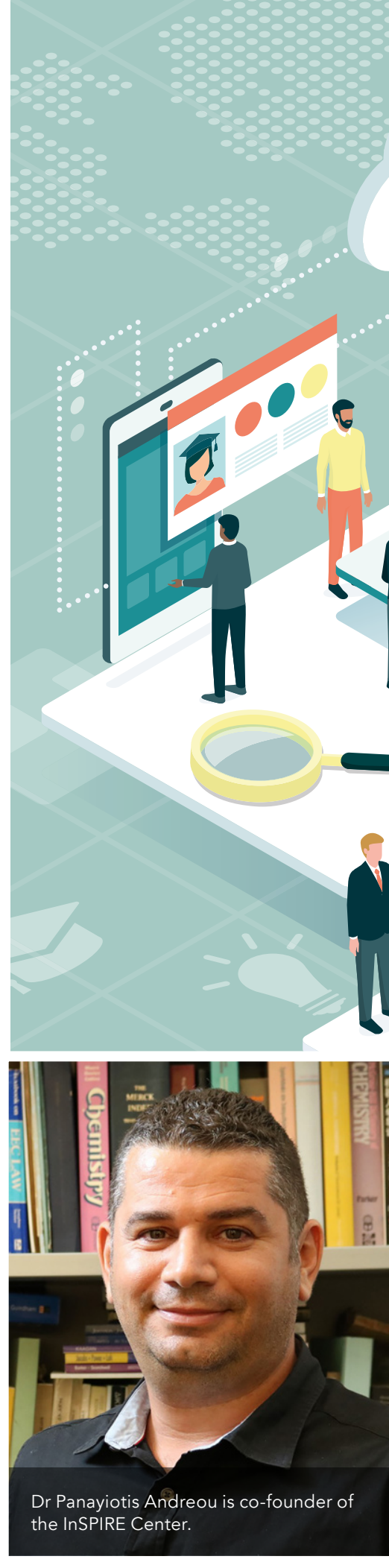

funded projects (e.g. the EU Framework Programmes, Engineering and Physical Sciences Research Council, eTEN programme, INFSO-ICT and Active \& Assisted Living programme).

Could you tell us a little bit about your background? How did you come to be In addition to being a founding member and co-director of InSPIRE,
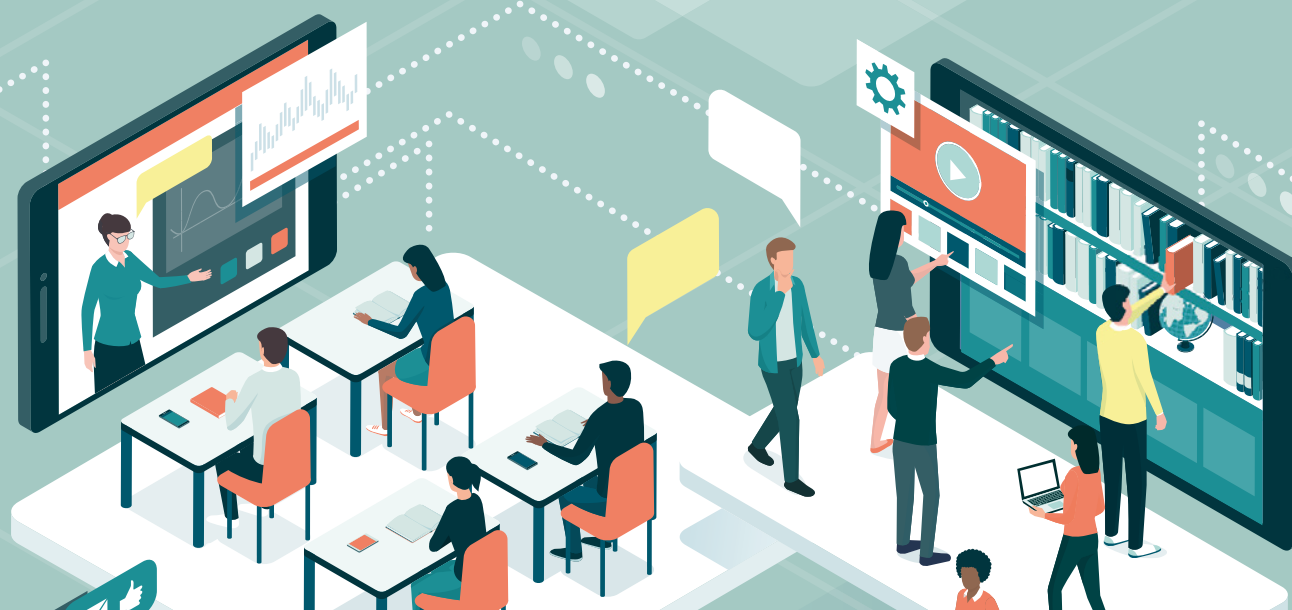
1

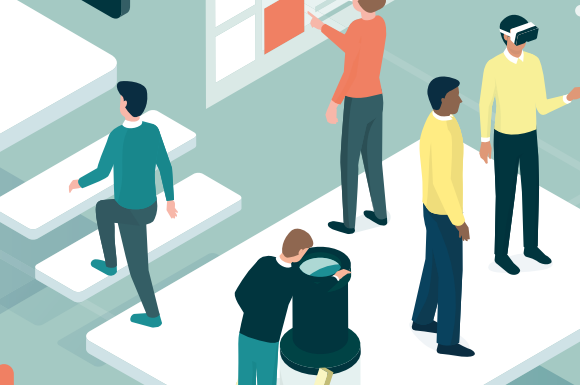
II 2

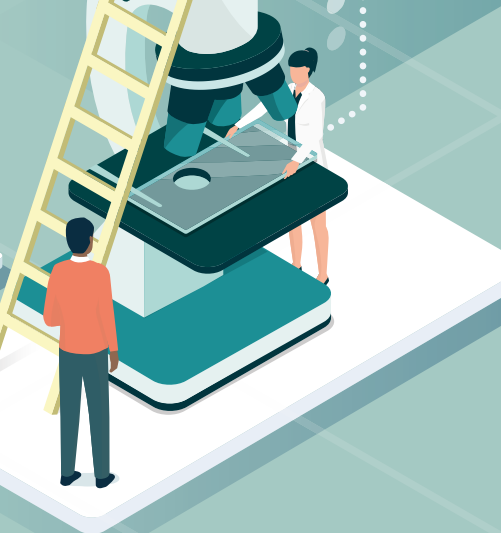

InSPIRE embraces an open innovation approach where staff, students and partners are encouraged to engage in interdisciplinary research and innovation.

Computing and the Course Leader of the MSc Data Analytics at the School of Sciences at UCLan Cyprus. I received in 2011, and in 2012 I spent one year as Marie-Curie post-doctoral researcher at the Portuguese company IDMind in Lisbon. My main research interests include data management and analy in networks and systems, adaptive computing, e- health and ambient assisted living. I was always fascinated by research, pursuing new knowledge an new ways to apply it. At the sage tro, from my eally years, had a
I acquired extensive experience in the design, development and deployment of software systems in the context of research and industry projects.

Being passionate about both worlds, esearch and industry, enabled me to find ways to gracefully blend them together in an impactul way. I became my work, I insu 2014 and through my work, lensured that my course informed and that my and industy opportunities to engage with industry opportunities to engage with industry take long to realise that I could not completely fulfill my vision within the set the knowledge and skills I considered succeed in a competitive and diverse global work environment. transferable skills can only be enhanced beyond the and through extra-curricular activities. This, combined with my a signifin on projects that will have and industry coct on the scientific tudents and communities and mentor such projects, gave bith to the idea InSPIRE, which, with the support of the Center's co-founder, Prof Irene 
